JOURNAL ${ }^{\circ}$

ZOOLOGICAL SYSTEMATICS

AO EVOLUTIONARY RESEARCH

\title{
New molecular data favor an anthropogenic introduction of the wood mouse (Apodemus sylvaticus) in North Africa
}

\begin{tabular}{|c|c|}
\hline Journal: & Journal of Zoological Systematics and Evolutionary Research \\
\hline Manuscript ID: & JZS.201500002.R2 \\
\hline Wiley - Manuscript type: & Original Article \\
\hline Date Submitted by the Author: & $\mathrm{n} / \mathrm{a}$ \\
\hline Complete List of Authors: & $\begin{array}{l}\text { Lalis, Aude; Muséum National d'Histoire Naturelle, UMR ISYEB } 7205 \\
\text { Leblois, Raphael; INRA, UMR } 1062 \\
\text { Liefrid, Sohaib; Université Abdelmalek Essaâdi, Faculté des Sciences } \\
\text { OUAROUR, Ali; Université Abdelmalek Essaâdi, Faculté des Sciences } \\
\text { REDDY BEERAVOLU, Champak; INRA, UMR } 1062 \\
\text { MICHAUX, Johan; Université de Liège, Unité de génétique de la } \\
\text { conservation } \\
\text { Hamani, Adel; ENSA, Département de Zoologie } \\
\text { Denys, Christiane; Muséum National d'Histoire Naturelle, UMR ISYEB } 7205 \\
\text { Nicolas, Violaine; Muséum National d'Histoire Naturelle, Paris, UMR } 7205\end{array}$ \\
\hline Keywords: & $\begin{array}{l}\text { Anthropogenic introduction, Demographic history, Mediterranean basin, } \\
\text { Population expansion, Rodent }\end{array}$ \\
\hline Abstract: & $\begin{array}{l}\text { According to fossil data the wood mouse arrived in North Africa 7,500 ya, } \\
\text { while it was present in Europe since early Pleistocene. Previous molecular } \\
\text { studies suggested that its introduction in North Africa probably occurred via } \\
\text { the Strait of Gibraltar more than } 0.4 \text { Mya ago. In this study, we widely } \\
\text { sampled wood mice in order to get a better understanding of the } \\
\text { geographic and demographic history of this species in North Africa, and } \\
\text { possibly to help resolving the discrepancy between genetic and } \\
\text { paleontological data. Specifically we wanted to answer the following } \\
\text { questions: (1) when and how did the wood mouse arrive in North Africa? } \\
\text { and (2) What is its demographic and geographic history in North Africa } \\
\text { since its colonization? We collected in the field } 438 \text { new individuals and } \\
\text { used both mtDNA and six microsatellite markers to answer these } \\
\text { questions. Our results confirm that North African wood mice have a } \\
\text { southwestern European origin and colonized the Maghreb through the } \\
\text { Gibraltar strait probably during the Mesolithic or slightly after. They first } \\
\text { colonized the Tingitane peninsula and then expanded throughout North } \\
\text { Africa. Our genetic data suggest that the ancestral population size } \\
\text { comprised numerous individuals reinforcing the idea that wood mice did } \\
\text { not colonize Morocco accidentally through rafting of a few individuals, but } \\
\text { via recurrent/multiple anthropogenic translocations. No spatial structuring } \\
\text { of the genetic variability was recorded in North Africa, from Morocco to } \\
\text { Tunisia. }\end{array}$ \\
\hline
\end{tabular}


1 New molecular data favor an anthropogenic introduction of the wood mouse (Apodemus 2 sylvaticus) in North Africa

4 Aude LALIS ${ }^{1}$, Raphael LEBLOIS ${ }^{2}$, Sohaib LIEFRIED ${ }^{3}$, Ali OUAROUR ${ }^{3}$, Champak 5 REDDY BEERAVOLU ${ }^{2}$, Johan MICHAUX ${ }^{4}$, Adel HAMANI ${ }^{5}$, Christiane DENYS ${ }^{1}$, 6 Violaine NICOLAS ${ }^{1}$

$8{ }^{1}$ Institut de Systématique, Evolution, Biodiversité ISYEB UMR 7205 - CNRS MNHN UMPC

9 EPHE, Muséum National d'Histoire Naturelle, Sorbonne Universités, 57 rue Cuvier, CP 51, 1075005 Paris, France

112 INRA, UMR1062 CBGP, F-34988 Montferrier-sur-Lez, France

$12{ }^{3}$ Laboratoire de Biologie et Santé, Université Abdelmalek Essaâdi, Faculté des Sciences, BP

13 2121, Tétouan, Maroc

$14{ }^{4}$ Unité de génétique de la conservation. Institut de Botanique, Université de Liège (Sart Tilman), 154000 Liège, Belgique.

$16{ }^{5}$ Laboratoire d'Ornithologie, Département de Zoologie, ENSA El Harrach, Alger, Algeria

18 Corresponding author:

19 Violaine NICOLAS, Institut de Systématique, Evolution, Biodiversité ISYEB UMR 7205 20 CNRS MNHN UMPC EPHE, Muséum National d'Histoire Naturelle, Sorbonne Universités, 57 21 rue Cuvier, CP 51, 75005 Paris, France. Tel : (33) 1407948 52, vnicolas@mnhn.fr

\section{Keywords}

24 Anthropogenic introduction; Demographic history; Mediterranean basin; Population expansion; 25 Rodent 


\section{Abstract}

According to fossil data the wood mouse arrived in North Africa 7,500 ya, while it was present in Europe since early Pleistocene. Previous molecular studies suggested that its introduction in North Africa probably occurred via the Strait of Gibraltar more than 0.4 Mya ago. In this study, we widely sampled wood mice in order to get a better understanding of the geographic and demographic history of this species in North Africa, and possibly to help resolving the discrepancy between genetic and paleontological data. Specifically we wanted to answer the following questions: (1) when and how did the wood mouse arrive in North Africa? and (2) What is its demographic and geographic history in North Africa since its colonization? We collected in the field 438 new individuals and used both mtDNA and six microsatellite markers to answer these questions. Our results confirm that North African wood mice have a southwestern European origin and colonized the Maghreb through the Gibraltar strait probably during the Mesolithic or slightly after. They first colonized the Tingitane peninsula and then expanded throughout North Africa. Our genetic data suggest that the ancestral population size comprised numerous individuals reinforcing the idea that wood mice did not colonize Morocco accidentally through rafting of a few individuals, but via recurrent/multiple anthropogenic translocations. No spatial structuring of the genetic variability was recorded in North Africa, from Morocco to Tunisia.

\section{Introduction}

North-Africa belongs to the Mediterranean region which is considered today as a biodiversity hotspot (Myers et al. 2000; 2002). Its remarkable diversity is derived from three sources: the northern Palearctic, sub-Saharan Africa and the arid Palearctic (Dobson and Wright 2000). For several species the timing and path of colonization of North Africa are under debate. Genetic data provide powerful tools to infer the geographical origin and colonization time of a given population. The wood mouse, Apodemus sylvaticus (Linnaeus 1758), is one example of these widely distributed species in both the Maghreb (Northwest Africa) and Western Europe. According to fossil data it only arrived recently, i.e. during the Holocene, in Morocco and Algeria (Stoetzel 2013), while it was present in Europe since early Pleistocene (Cuenca-Bescós et al. 2010; Michaux and Pasquier 1974). Several hypotheses have been formulated to explain the arrival of the wood mouse in the Maghreb region (Libois et al. 2001): the species would have 
59 actually absent, via the Libyco-Egyptian route, or from Western European regions such as Sicily,

60 via the Siculo-Tunisian strait, or Spain, via the strait of Gibraltar (Fig. 1). First, as a result of 61 glacial and inter-glacial cycles during the Pleistocene, the current desert regions of northern 62 Egypt, Libya and the Near East were not always arid (Groves and Di Castri 1991; Langgut et al. 63 2011; Migowski et al. 2006) allowing the migration of several species. According to fossil data, 64 A. sylvaticus was present in Libya during the upper Paleolithic from 35,000 to 10,000 ya (Jaeger 65 1975), in Israel from Mindel/Riss (i.e. 450- $300 \mathrm{ka}$ ) to recent times (Cheylan 1991; Tchernov 66 1979), and in Turkey from 350 to $60 \mathrm{ka}$ (Demirel et al. 2011). All these arguments favor the 67 existence of a potential Libyco-Egyptian route of migration. However, it is well known that $A$. sylvaticus and A. flavicollis (Melchior 1834) are phenotypically highly similar species, unidentifiable in South and Eastern Europe at the individual level by morphological methods used by paleontological approach (Jojić et al. 2014). Moreover, the species identification of specimens from Turkey and Israel should be confirmed since several taxa from the Middle East previously assigned to $A$. sylvaticus were recently identified as a different species (Filippucci et al. 2002). Second, the two migration routes through southern Europe are often proposed to explain the close affinity between European and North African mammal fauna at different periods of the Pleistocene (Arambourg 1962; Jaeger 1975; Stoetzel 2013). Moreover, several genetic studies recently showed that both the strait of Gibraltar and the strait of Sicily allowed the crossing in both senses of numerous animals during the Pleistocene period, either via natural colonization or via incidental human introduction (Cosson et al. 2005; Guillaumet et al. 2006; Habel et al. 2009; Recuero et al. 2007; Stöck et al. 2008).

80 Based on mitochondrial DNA (mtDNA) restriction patterns and cytochrome b (cytb) sequences 81 Libois et al. (2001) and Michaux et al. (2005; 2003) suggested that the introduction of the wood 82 mouse in North Africa probably occurred via the Strait of Gibraltar 0.4 Ma. This dating does not 83 fit the paleontological data; the oldest fossil of wood mouse in North West Africa being dated of 847,500 ya (Stoetzel 2009, 2013). Discrepancies between molecular and paleontological data may 85 be partly due to the limited number of North African specimens ( 8 to 28) and localities (2 to 7) 86 previously considered in molecular studies. These authors stressed the necessity to get a better 87 sampling in North Africa and South Western Europe to better identify the centre of origin of 88 African populations and to confirm the lack of genetic variability throughout the African range of 89 the species. Moreover previous divergence time analyses were based on substitution rates 
90 inferred from a phylogeny. It is now well known that the mutation rate is much higher than the

91 substitution rate, and that the relationship between mutation and substitution rates can be

92 described by an exponential curve (Ho et al. 2005). This means that molecular rates should be

93 interpreted in the context of calibration point age and that short-term mutation rates can only be

94 extrapolated to older times after accounting for the relationship between short-term and long-term

95 rates of change. Ho et al. stressed that taking rate variation into account is particularly important

96 for analyses of sequences on timescales of less than about 1-2 Myr before the present, such as

97 studies on populations, which often incorrectly apply phylogenetic substitution rates to

98 population-level analyses. Because Michaux et al. $(2005 ; 2003)$ did not take this into account,

99 their results need to be reevaluated.

100 In this study, we widely sampled wood mice in North Africa (Fig. 1) in order to get a better

101 understanding of the geographic and demographic history of this species in this region, and

102 possibly to help resolve the discrepancy between genetic and paleontological data. We also

103 considered new specimens from Europe in order to get a better idea of the geographic origin of

104 North African populations. Finally, we used a new approach to estimate the mutation rate for our

105 intraspecific phylogeny. Specifically we wanted to answer the following questions: (1) when and

106 how did the wood mouse arrive in North Africa? and (2) What is its demographic and geographic

107 history in North Africa since its colonization? Due to its numerous advantages such as high rate

108 of evolution, lack of recombination and haploidy, mtDNA has been widely used as a classical

109 phylogeographic marker (Brito and Edwards 2009). However, because of its maternal

110 inheritance, the risks of introgression and the absence of independent information coming from

111 unlinked locus, mtDNA also presents some inconveniences and could yield to biased historical

112 inferences. Therefore, we used both mtDNA cytb sequences and six microsatellite markers to

113 study the genetic structure and demographic history of the wood mouse in North Africa.

\section{Material and methods}

\section{Ethics Statement}

117 Animals were live-trapped and handled under the guidelines of the American Society of 118 Mammalogists (Sikes et al. 2011). The protocol was approved by Comité Cuvier (permission no. 119 68.009). All manipulations of animals were made in Morocco in agreement with the global law 120 11-03 relative to the protection and the development of the environment. Alive animals were 
121 euthanized by the injection of a lethal dose of isofluorane, followed by cervical dislocation.

122 Capture permits were obtained through the "Haut Commissariat aux Eaux et forêts et à la Lutte 123 contre la désertification" (autorisation $\mathrm{n}^{\circ} 15 \mathrm{HCEFLCD/DLCDPN/DPRN/CFF)} \mathrm{in} \mathrm{Morocco,} \mathrm{and}$

124 through the Ministry of Forestry in Algeria.

125

Sampling and DNA extraction

127438 newly collected individuals were included in this study (23 specimens from 5 French 128 localities, 2 specimens from one locality in Portugal, 40 specimens from 4 Spanish localities, 19 129 specimens from 2 Algerian localities, 334 specimens from 12 Moroccan localities, 1 specimen 130 from Denmark, 19 specimens from Sweden; Supplementary Table S1). Genomic DNA was 131 extracted from tissues preserved in 95\% ethanol using NucleoSpin Tissue Core kit 132 (MACHEREY-NAGEL).

Mitochondrial DNA amplification and sequencing

135 The cytb gene was amplified for 375 individuals using polymerase chain reaction (PCR) primers L14723, H15915 (Ducroz et al. 2001), ApoIntL2 (CTGGATCWAAYAACCCAACA) or ApoIntH1 (GTGGGGTRTTWAGTGGGT; this study). The internal primers designed in this study were used to amplify the DNA of the Iberian specimens, for which DNA was degraded. PCR conditions and sequencing followed Nicolas et al. (2014). The presence of cytb pseudogenes is well documented in Apodemus (Dubey et al. 2009). Pseudogenes are usually characterized by the presence of indels, stop codons, frame-shift mutations and amplification of heterozygotes (Frezal and Leblois 2008; Trian and DeWoody 2002). We have not observed any of these indications in our dataset. Moreover the base composition per codon was not significantly different between individuals. So we believe that pseudogenes were not present in our dataset. Sequences were submitted to the Genbank database (KM581675 to KM582049).

\section{Microsatellite genotyping}

148 Six loci were genotyped for 295 individuals. These six loci, As-20, As-34 (Harr et al. 2000) and

149 GTTC4A, GTTD8S, GTTD9A, TNF(CA) (Makova et al. 1998) were selected based on length, 150 annealing temperature, and quality of allele amplification. PCR conditions followed Harr et al. 151 (2000) and Makova et al. (1998). PCR products were run and genotypes were scored according 
152 to Lalis et al. (2012). Those loci were genotyped on the seven Moroccan populations with sample 153 sizes varying from 23 individuals (ElKhizana) to 92 individuals (Taza) (Supplementary Table S1)

Mitochondrial DNA analyses Phylogenetic analysis

157 In our phylogenetic analyses we included all the newly sequenced specimens and all specimens 158 available in the Genbank database for which the cytb gene was sequenced, except those 159 considered as pseudogenes by Dubey et al. (2009). This represents 545 individuals 160 (Supplementary Table S1: 375 newly sequenced specimens and 170 specimens from Genbank). 161 Phylogenetic relationships between haplotypes were inferred by constructing a network using the 162 median-joining (MJ) method available in NETWORK v4.500 (Bandelt et al. 1999). This method 163 accounts for the coexistence of ancestral and descendent haplotypes, multifurcations, and reticulate relationships (Posada and Crandall 2001) and it is therefore suitable for studying intraspecific relationships. We used the MP post-processing option, which removes all superfluous median vectors and links that are not contained in the shortest trees of the network. Sequences of $701 \mathrm{bp}$ were retained for the network analysis in order to minimize the number of incomplete sequence as adding ambiguous data in median joining trees is problematic.

170 Nucleotide diversity and haplotype diversity (Nei 1987) were calculated using DnaSP 5.10 171 (Librado and Rozas 2009). This paper focuses on the colonization and subsequent demographic 172 and geographic history of $A$. sylvaticus in North Africa. Thus, estimates of demographic history 173 and spatial structure are only provided for this geographical region. $864 \mathrm{bp}$ were available for all 174 sequences from Maghreb, thus our demographic analyses are based on this sequence length. We 175 analyzed population structure with an analysis of molecular variance (AMOVA). A population 176 was defined as all individuals coming from one geographical locality. $F_{\mathrm{ST}}$ values were also 177 calculated between all pairs of populations. Moreover, the plausibility of an isolation-by-distance 178 scenario was explicitly tested by performing Mantel's tests (Mantel 1967) following the 179 procedure described in Nicolas et al. (2014). All these analyses were performed using 180 181 ARLEQUIN 3.11 (Excoffier et al. 2005)

Demographic history 
182 The demographic history of populations was inferred using $\mathrm{Fu}$ 's $F_{\mathrm{s}}$ test of population growth $(\mathrm{Fu}$ 183 1997). This statistics was estimated using ARLEQUIN 3.11, and its significance was assessed 184 using 1000 coalescent simulations. As suggested in the ARLEQUIN manual, the $F_{\mathrm{s}}$ statistics was 185 considered significant when the $p$-value was below 0.02 .

186 We also used a test based on mismatch distributions in each population to determine if a 187 population expansion occurred in the past, and to characterize it (Rogers and Harpending 1992).

188 Excoffier et al. (2005) proposed to use these mismatch distributions to select between two 189 models: a 'pure demographic expansion' and a 'spatial expansion'. Both assume that a stationary 190 haploid population of size $N_{0}$ suddenly grew $T$ generations ago to reach a population size of $N_{1}$ 191 haploid individuals. However, while the 'pure demographic expansion' model assumes that the 192 growing population is panmictic, the 'spatial expansion' model involves a spatial range 193 expansion and spatially structured populations. To test the fit of these two models to our data, as 194 well as to estimate the scaled expansion time $\tau=T^{*} 2 \mu / G$ ( $\mu$ is the mutation rate per sequence per 195 generation; $G$ is the generation time) and migration rate parameter $M=N m$ in the second model, 196 we used the least square fitting algorithm implemented in ARLEQUIN 3.11. Model choice and 197 CI for parameter estimates are based on a parametric bootstrap approach. The generation time can 198 vary within this species according to ecological conditions (Fons and Saint Girons 1993), but it is 1990.5 year in Morocco and Algeria (Harich and Benazzou 1990).

200 Demographic history was also explored using the MIGRAINE software and the newly developed 201 model of a single population with past variations in population size (Leblois et al. 2014). The model of past change in population size implemented in MIGRAINE is similar to that used in the mismatch analysis except that past variation in population size is exponential and not discrete/sudden. MigRAINE was used to estimate ancestral theta $\left(\theta_{\text {anc }}=2 N_{\text {anc }} \mu\right.$, where $N_{\text {anc }}$ is the ancestral haploid population size and $\mu$ the mutation rate of the whole sequence), current theta $(\theta=2 N \mu$, where $N$ is the current population size) and $D$, the time of occurrence of the demographic change scaled by population size (i.e. $D=T / 2 N G$, where $T$ is expressed in years and

$208 \mathrm{G}$ is the generation time). Because Migraine is based on the infinite sites model (ISM) for analysis of sequence data, two datasets were produced for the mtDNA cytb region to fit this model. For one data set, we chose to systematically remove incompatible sites for all individuals,

211 for the second, we chose to remove haplotypes with incompatible sites. For all analyses, we 212 pooled all individuals from Morocco because of the clear lack of genetic structure observed in 
213 our sample. All runs with MigRAINE were done using 1,000,000 trees, 2400 points and two 214 iterations.

215 To get an inference of the time of occurrence of the past expansion, we need to compute the 216 unscaled parameter $T$ from the scaled time parameters inferred by the different methods using a 217 given mutation rate and a generation time. However an accurate estimation of the mutation rate is 218 usually difficult to obtain. Both intraspecific and pedigree-based estimates of substitution rates 219 are generally higher than interspecific phylogenetically calibrated rates (Ho et al. 2005). This 220 difference is due to purifying selection. To accurately estimate mutation rate for intraspecific 221 phylogenies it is thus recommended to focus on synonymous mutations because under the assumption of neutral evolution, the substitution rate for synonymous mutations is equal to the mutation rate (Kimura 1968). Nabholz et al. (2008) recently re-evaluated the evolutionary

224 substitution rate at the third codon position of the cytb using a multi-point calibration procedure 225 of lineage-specific mutation rates across 1696 mammalian species. They found that Rodentia is 226 the fastest evolving order, with an average of $1.7610^{-07}$ substitution per site per year, and that the 227 mutation rate can vary greatly among rodents taxa. Thus we decided to infer a specific mutation 228 rate using cytb data, from the third codon position only, for the genera Apodemus and two 229 calibration points derived from paleontological data. The divergence time between A. mystacinus 230 (Danford and Alston 1877) and A. flavicollis/A. sylvaticus was estimated to be approximately 7 231 My old, and the divergence between A. sylvaticus and A. flavicollis to be approximately 4 My old 232 (Michaux et al. 2004; Michaux et al. 2003). All cytb sequences of 864 bp of $A$. mystacinus and $A$. 233 flavicollis available in the Genbank database were included in our analyses (i.e. 1 and 34 234 sequences respectively), and considering the third codon positions only results in a data set 235 containing $288 \mathrm{bp}$ per individual sequence. The mean number of substitutions between $A$. 236 mystacinus and A. flavicollis/A. sylvaticus was 116, and 75 between $A$. sylvaticus and $A$. 237 flavicollis. Assessing the variation of synonymous substitution rates between lineages is 238 technically problematic because of saturation. To minimize this effect of multiple mutations at 239 one site, we based our computations on the number of sites that are similar between the two 240 species rather than on the segregating ones. According to Felsenstein (2004), the probability of 241 observing a site with a similar state is $\frac{1+e^{-2 \mu t}}{2}$, where $\mu$ is the mutation rate and $t$ is the 242 divergence time, both expressed in the same unit (i.e. generations or years) between the two 
243 species. Given this formula, we obtained a mutation rate of $1.210^{-07}$ substitution per site per year

244 for the calibration A. mystacinus and A. flavicollis/A. sylvaticus, and a mutation rate of $0.910^{-07}$

245 substitution per site per year for the calibration A. sylvaticus/A. flavicollis.

Microsatellites analyses

Genetic diversity

249 Genetic variability of the microsatellite markers was measured for each locus by the number of

250 alleles $\left(N_{\mathrm{a}}\right)$, gene diversity $\left(H_{\mathrm{e}}\right.$, expected heterozygosity), and observed heterozygosity $\left(H_{\mathrm{o}}\right)$ using

251 R package adegenet v1.2-7 (Jombart 2008). Allelic richness, tests for Hardy-Weinberg

252 equilibrium (HWE) and linkage disequilibrium were conducted according Lalis et al. (2012). We

253 then used the software FREENA (Chapuis and Estoup 2007) to estimate null allele frequencies

254 (a) for each population and locus following Dempster et al. (1977).

\section{Population structure}

257 We applied STRUCTURE v2.3.3 (Pritchard et al. 2000) to the data with K varying from 1 to 6, 258 with 5 runs for each $\mathrm{K}$ value. The number of contributing populations was statistically tested 259 using the ad-hoc Evanno statistic DK (Evanno et al. 2005). This procedure is sensitive to 260 pronounced changes in mean log likelihood values between successive $\mathrm{K}$ values and the degree 261 of variance of any given mean.

262 We also analyzed the spatial genetic structure with the software GENELAND v2.5.0 (Guillot et 263 al. 2005) which uses geographic information to identify spatial discontinuities in the genetic 264 structure of the sample. We first performed a preliminary analysis with 10 runs of 1000000 265 iterations with a thinning of 500 and a burn-in of $50 \%$, considering values for $\mathrm{K}$ from 1 to 6 with a starting value of 2 , to infer the number of populations $\mathrm{K}$ maximizing the posterior probability of the data. Then longer runs (ten replicates, each) of 20000000 iterations with a thinning of 500 and burn-in of $50 \%$ were analyzed to precisely set the spatial limits for $\mathrm{K}=2$ (first split). For all analyses, the uncertainty attached to spatial coordinates was set to $0.2 \mathrm{~km}$ and the maximum number of nuclei in the Poisson- Voronoi tessellation fixed at 1800 (roughly three times the number of analyzed individuals).

272 Population differentiation was further analyzed by computing estimates of $F_{\mathrm{ST}}$ (Weir and

273 Cockerham 1984) between all population pairs using GENEPOP v4.1.3 and significance was 
274 tested by permutation using FSTAT (Goudet 1995; Goudet et al. 1996). Using GENEPOP, we

275 also looked for isolation by distance patterns by regressing $F_{\mathrm{ST}} /\left(1-F_{\mathrm{ST}}\right)$ between populations over 276 the logarithm of geographical distances as recommended by Rousset (1997), and significance of 277 the correlations between genetic and geographic distances was tested using Mantel tests with 27830,000 permutations.

\section{Demographic history}

The MigRAINE software was also used on the microsatellite data set to infer past changes in population sizes. All MigRAINE runs for microsatellites used 20,000 to 200,000 trees, 2,400 points and 3 iterations. To convert our estimates of scaled parameters into unscaled demographic parameters we considered a fixed value of $510^{-4}$ mutation per locus per generation for all microsatellite loci (Dib et al. 1996; Ellegren 2000; Sun et al. 2012).

\section{Results}

288 Genetic diversity and structure of the wood mouse across its geographic range

289 Our MJ network analysis shows that the 545 A. sylvaticus cytb sequences fell into two major 290 lineages (Fig. 2, Supplementary Figure S1); the first one comprising the Italian, Balkan and 291 Sicilian animals (lineage 1), and the second corresponding to all specimens from North Africa 292 and western, northern and central Europe (lineage 2). The first lineage is divided into two 293 sublineages: a Sicilian one (lineage 1b) and an Italo-Balkan one (lineage 1a). The second lineage 294 is also divided into two sublineages: a North African group (lineage 2a), and a Western, Northern 295 and Central Europe group - lineage 2b). In North Africa the network has a starlike pattern with 296 one very common ancestral haplotype widely distributed in Morocco, Algeria and Tunisia. The 297 pattern obtained in lineage $2 \mathrm{~b}$ is much more complex, with a high number of haplotypes 298 represented by few individuals and high genetic distances between haplotypes. The number of 299 Spanish haplotypes is especially high (Fig. 2). Several starlike patterns are observed within 300 lineage $2 \mathrm{~b}$ : the central and most common haplotypes are often found in Spain, except one case 301 where the central haplotype is found in Northern Europe (Sweden, Netherlands, Denmark, Czech 302 Republic and Belgium). The European haplotype closest to Maghrebian ones is found in Sweden. 303 According to our MJ network analysis, we have at least 7 mutations (all in third codon position) 304 between Maghrebian and European haplotypes. This corresponds to a time of divergence of 
85,000-165,000 ya, depending on mutation rate (Calibration 1 (mutation rate of $1.210^{-07}$ substitution per site per year obtained from comparison between A. mystacinus and $A$. flavicollis/A. sylvaticus haplotypes) gave a divergence time of 125,000 ya. Calibration 2 (mutation rate of $0.910^{-07}$ substitution per site per year obtained from comparison between $A$. sylvaticus and A. flavicollis haplotypes) gave a divergence time of 165,000 ya. Calibration 3 (mutation rate of $1.7610^{-07}$ substitution per site per year according to Nabholtz et al. (2008)) gave a divergence time of 85,000 ya).

312 Haplotype diversity is similar between lineages 1a, 2a and $2 \mathrm{~b}$ and tends to be a little higher than

313 in lineage 2a (Table 1). Nucleotide diversity is 2.1 to 2.9 times lower in the Maghrebian lineage

314 than in the three other lineages. Within the Maghrebian lineage, haplotype diversity is lower in 315 Merja Zerga than in other populations. Within lineage $2 b$ haplotype diversity is 1.2 to 1.5 times 316 higher in the two Spanish populations than in France or Sweden, while nucleotide diversity is 1.4 317 to 3.7 times higher.

319 Genetic diversity and structure of the wood mouse in North Africa

320 All microsatellite loci show a high genetic diversity: the total number of alleles per locus ranged 321 from 1 to 19 with a mean number of 9 alleles per locus (Supplementary Table S3). Among the 6 322 loci, four (As-34, GTTC4A, TNF(CA) and As-20) show significant heterozygote deficiencies and 323 have deviations $(<\mathrm{P}=0.05)$ from mutation-drift equilibrium for an excess of heterozygosity 324 (Supplementary Table S3). Using FREENA, we show that the most probable hypothesis to 325 explain heterozygote deficiencies in these loci is the existence of null alleles. Mean estimated null 326 allele frequencies are moderate (mean frequency $\bar{a}$ (As-34) $=0.067, \bar{a}(\mathrm{GTTC} 4 \mathrm{~A})=0.079, \bar{a}$ $327(\mathrm{TNF}(\mathrm{CA})=0.037$ and $\bar{a}($ As-20) $=0.012)$. Overall the loci were judged statistically independent.

328 The number of alleles per population ranges from 8 to 13 with a mean number of alleles per 329 population of 9 (Table 4). The expected heterozygosity is relatively high. According to locus and 330 population, it varies between 0.600 and 0.775 (Supplementary Table S3).

331 We applied two complementary clustering algorithms to infer rodent population structure and to 332 probabilistically assign individuals to populations or clusters based on individual multilocus 333 genotypes. STRUCTURE 2.3.3 provided consistent results over 5 replicated runs and the 334 probability of the data $(\mathrm{LnP}(\mathrm{K}))$ increased from $\mathrm{K}=1$ to $\mathrm{K}=6$ although with a clear tendency to 335 reach a plateau at $\mathrm{K}=4$ and higher values (Figure 3 ). According to the Evanno test, $\mathrm{K}=2$ and $\mathrm{K}=3$ 
336 are the most likely scenario: all populations are grouped except population MerjaZerga. 337 STRUCTURE results for $\mathrm{K}=2$ are fully congruent with the GENELAND bipartition (Fig3). The 338 plot is based on the highest-probability run for $\mathrm{K}=2$ (the same split and similar posterior 339 probabilities were obtained for all 20 replicates).

340 For the mtDNA data $9 \%$ of the genetic variation is partitioned among populations and $91 \%$ 341 within populations $\left(\mathrm{F}_{\mathrm{ST}}=0.091, \mathrm{P}<0.001\right) . F_{\mathrm{ST}}$ values between most pairs of populations are 342 low (range from 0.007 to 0.199$)$ but significantly different from $0(\mathrm{P}<0.05)$, except between the 343 population of El Khizana and the populations of Chrouda, Parc Talassemtane, Taza and Ifrane 344 which are not significant (Supplementary Table S2). For microsatellite data, multilocus estimates 345 of $F_{\mathrm{ST}}$ for pairs of populations range from -0.004 to 0.095 (Supplementary Table S4).

346 No significant correlation between geographic and genetic distances is recorded in all Maghreb 347 samples based on both mt DNA ( $\mathrm{P}$ value of Mantel test $=0.682)$ and microsatellite data $(\mathrm{P}=$ 348 0.211).

350 Demographic history of the wood mouse in North Africa

351 A clear signal of population expansion is observed in the North African clade based on $F_{\mathrm{s}}$ (Table 352 1), mismatch analyses (Table 2, Supplementary Figure S2) and Migraine analyses (Table 3, 353 Supplementary Figure S3). These results are also corroborated by the starlike pattern observed in 354 the MJ network. Based on mismatch analyses, a signal of demographic and/or spatial expansion 355 is recorded in the populations of Cap Djinet, Beni Hadifa, Chrouda, El Khizana, Ifrane, Parc 356 Talassemtane and Taza. Estimates of the migration parameter $M(M=2 N m)$ are very large $357(99,999)$ for these populations, meaning that a very low level of population structure is inferred 358 under the spatial model for these samples. For every values of the migration parameter, both 359 models are equivalent. On the contrary, for the population of Merja Zerga, the test based on $F_{\mathrm{s}}$ is 360 not significant, and the mismatch distribution fits the spatial expansion model with an $M$ value of 3613 (CI: 0-34) but not the demographic expansion model.

362 Based on mismatch analyses, the timing of the expansion was calculated for three distinct 363 mutation rates (Table 2) and a generation time of 0.5 year. Values vary of a factor 2 according to 364 the mutation rate used, and confidence intervals are large. However all analyses show that the 365 expansions probably occurred in early Holocene or late Pleistocene (mean values vary between 
$3667,319-15,674$ ya to $14,287-30,596$ ya according to the mutation rate; CI vary from $819-12,503$ to $36714,181-45,259$ уа).

368 MIGRAINE analyses of both modified data sets fitting the ISM give very similar results suggesting 369 that modifications done to fit the ISM were not too drastic. In both cases, a highly significant 370 signal of past expansion is found, with (1) very high and precise estimates of current scaled 371 population sizes around $\theta=58$; (2) very low but imprecise estimates of ancestral scaled population 372 sizes around $\theta_{\text {anc }}<0.002$; and (3) estimations of the time from present to the start of the expansion 373 around $D=0.053$ with an intermediate precision (Table 3, Supplementary Figure S3). Considering 374 a mutation rate of $10^{-7}$ per site and per year, and correcting this mutation rate for the 375 modifications made on the data sets to fit the ISM (i.e. using a correction ratio of $C R=66 / 45$ and 376 67/75 kept sites), we can convert scaled population sizes into diploid effective population sizes 377 with the following computations $N=\theta /(C R *$ sequence length * mutation rate site per site per year $378 *$ generation time). For a generation time of 0.5 year, these calculations give point estimates of 379 current effective population size around 4.5 millions individuals [CI range: 2,900,000 $3808,300,000]$, ancestral population sizes of few hundred individuals [1 - 165,000] and a time of 381 occurrence around 125,000 years [22,000 - 340,000]. However, taking into account uncertainty 382 contains in the $95 \%$ confidence intervals of the scaled parameters makes converted IC very wide, 383 showing very limited precision for higher estimates. For example, 95\% CI for the time in years 384 are [14,000-620,000].

385 For the microsatellite data, MIGRAINE was initially run on all population samples independently. 386 However, probably because of low sample sizes, results by population do not show any 387 significant signal of past changes in population size, except for the Taza population, which had 388 by far the largest sample size, and for which a significant signal of population expansion is found 389 (data not shown). For this reason, and, because almost no population structure is observed on the 390 whole Moroccan samples, Migraine was thus finally run on the pooled Moroccan sample (i.e. all 391 Moroccan populations analyzed as a single population; Table 3). MiGRAINE results show a highly 392 significant signal of past expansion with parameter estimations that are concordant with those 393 obtained with the mtDNA data, with large current scaled population sizes (i.e > 8.6), intermediate 394 ancestral population sizes and recent timing in terms of $T / 2 N$. However, precision of the 395 estimations are almost opposite to that obtained on the mitochondrial data as the best precision is 396 obtained for the scaled ancestral population size estimate with a very narrow CI of 5.4-20.4 for a 
397 generation time of 0.5 year, whereas current population sizes and timing show much wider CIs.

398 We obtained point estimates of current population size of 160,000 [11,600-1,400,000]

399 individuals, ancestral population sizes of 7,200 [2,800-10,200] individuals and a time of 135 [1-

$400344,000]$ years. The very high uncertainty level attached to the inference of the time in years is

401 due to the incertitude of the scaled time inferences multiplied by the incertitude of the diploïde 402 population size used for conversion (i.e. $D=T / 2 N$ ).

\section{Discussion}

405 Wood mouse phylogeography and origin of North African populations

406 Our results confirm the phylogeographical structure previously obtained by Libois et al. (2001) 407 and Michaux et al. $(2005 ; 2003)$ with four main lineages: a Sicilian lineage, an Italo-Balkan 408 lineage, a North African lineage and a western, northern and central Europe lineage. Compared to 409 these three previous studies, new specimens from Bosnia and Herzegovina, Macedonia and 410 Montenegro fall, as expected, in the Italo-Balkan clade. New specimens from Ireland, 411 Swizerland, Denmark, Sweden, France, Spain and Portugal fall, as expected, in the western, 412 northern and central Europe clade. New specimens from Morocco and Algeria fall in the North 413 African lineage.

414 Our MJ network analysis strongly suggests that North African wood mice have a 415 western/northern/central European origin. This is supported by the absence of genetic affinities 416 between all North African wood mice with either the Sicilian, Italian, or Balkan populations. 417 Gemmeke et al. (1987) also found that the A allele of transferrin is shared by Tunisian and 418 western European (Portugal, Spain, France, Germany) wood mice, whereas the animals of the 419 Tyrrhenian-Drisatic region (Italy, Sardinia, Croatia) are characterized by the presence of the B 420 and $\mathrm{C}$ alleles. Both Libois et al. (2001) and Michaux et al. (2003) suggested that wood mice 421 introduction into North Africa occurred via the Strait of Gibraltar, the genetically nearest 422 European haplotype coming either from the central part of the Iberian Peninsula (Libois et al. 423 2001) or from the central part of Portugal (Michaux et al. 2003). However, based on larger 424 sample sizes, our analyses show that the nearest European haplotype to the Maghrebian ones 425 comes from Sweden. The high haplotype and nucleotide diversities observed in the two Spanish 426 populations (Table 1) suggest that the Iberian Peninsula was a refuge region for A. sylvaticus 427 during the last glacial maximum, and that wood mice recolonized and expanded in the main part 
428 of the Western Palearctic region from there at the end of the last ice age (Michaux et al. 2005;

429 Michaux et al. 2003). Thus, the close affinity between haplotypes from Morocco and Sweden 430 may be due to the large geographic genetic variability with limited sampling: we sampled only a 431 restricted number of localities in Spain (7) and Portugal (1) and probably underestimated the 432 genetic diversity within the Iberian Peninsula. Moreover, in a recent review Gomez and Lunt 433 (2007) showed that Iberia was not a single refuge during the Pleistocene glacial maxima, but that 434 at least seven glacial refugia existed for terrestrial taxa ('refugia within refugia hypothesis'). We 435 sampled less than four of them. Extensive sampling of wood mice in Iberia would be necessary to 436 test the 'refugia within refugia' hypothesis on this species and its impact on the phylogeographic 437 history of European and North African wood mice. It is interesting to note that the sequencing of 438 the entire human mtDNA reveals that the Saami of Scandinavia and the Berbers of North Africa 439 share an extremely young branch, aged merely approximately 9,000 years (Achilli et al. 2005).

440 According to these authors this finding not only confirms that the Franco-Cantabrian refuge area 441 of southwestern Europe was the source of late-glacial expansions of hunter-gatherers that 442 repopulated northern Europe after the last glacial maximum, but also indicates that European 443 hunter-gatherers crossed the Strait of Gibraltar.

444 According to our mismatch analyses, oldests time of expansion were recorded in the populations 445 of Chrouda, Taza and El Khizana (i.e. close to the Tingitane Peninsula and the Gibraltar Strait) 446 and the youngest one in the Algerian population of Cap Djinet (i.e. Far East from the Gibraltar 447 Strait). This result reinforces the idea that the Maghreb was colonized from Iberia through the 448 Gibraltar Strait.

450 Crossing the Gibraltar Strait: the when and how of African colonization

451 Today, for a small terrestrial species, the Gibraltar Strait is an important barrier to dispersal, 452 being $14 \mathrm{~km}$ wide at its narrowest point and (currently) exceeding $200 \mathrm{~m}$ in depth. It is therefore 453 interesting to evaluate the timing and dynamics of colonization of African wood mouse from the 454 Iberian Peninsula to the Maghreb. European wood mice could have colonized Africa either via a 455 land bridge connecting the two continents, or after the opening of the Gibraltar Strait, either by 456 rafting on vegetation, or in recent times via anthropogenic means.

457 Geological evidence indicates that Morocco and the Iberian Peninsula have been connected by a 458 land bridge only twice (Blondel and Aronoson 1999; Duggen et al. 2003; Krijgsman et al. 1999): 
459 during the Betic crisis (16-14 Ma) and during the Messinian salinity crisis (5.59-5.33 Ma). Our 460 mtDNA analysis suggests that Africa was colonized less than 85,000-165,000 ya. These dates are 461 too recent to be consistent with dispersal via either of these land bridges.

462 An alternative possibility is suggested by the bathymetry of the Strait of Gibraltar and climatic 463 events during the Pleistocene period. The floor of the strait has a very complex topography 464 including several ridges, so that depths vary greatly (Brandt et al. 1996). The shallowest sections 465 are on an almost straight line from Cape Malabata in Morocco to Punta Paloma in Spain. On this 466 eminence, known as the Camarinal Sill, the present maximum water depth is $290 \mathrm{~m}$, but in many 467 places it is much shallower, ranging between 40 and $150 \mathrm{~m}$ (Brandt et al. 1996). Given that sea 468 levels in the area of the Strait of Gibraltar dropped by approximately $130 \mathrm{~m}$ during Pleistocene 469 glaciations (Andersen and Borns Jr. 1997), some of the higher parts of this area of the Camarinal 470 Sill are likely to have been exposed at that time as temporary small islands. Islands probably 471 formed visible land masses covered by vegetation, completely changing the appearance of the 472 strait from either shore. When sea levels were low, the maximum distance between two land 473 masses from Morocco to Spain was only about five kilometers (Straus 2001). This may have 474 enabled some terrestrial vertebrates to 'hop' across the Strait of Gibraltar quite recently, as 475 suggested for snakes (Carranza et al. 2006). Apodemus sylvaticus is clearly unable to swim the 476 distance between Africa and Europe, and even between either of the two continents and the 477 Mediterranean islands. However, rafting on a natural support may potentially have occurred, even 478 though biogeographical data concerning the western Mediterranean (Dobson 1998) and other 479 parts of the world (Heaney 1986) suggest that such events are extremely rare.

480 It is also possible that human activities led to translocation of A. sylvaticus from Spain to 481 Morocco, as previously shown for several other mammal species (Dobson 1998). Controversy 482 about possible trans-Gibraltar human movements in the Lower, Middle and even Upper 483 Pleistocene has reigned for over a century and continues to do so. According to the most recent 484 review (Rolland 2013), Europe was peopled independently by converging population movements 485 from both the Western Asian and Ibero-Moroccan staging posts during the Early Pleistocene, 486 between ca. 1.85-1.40 Ma. During brief, though favorable warm to cold transition periods, 487 purposeful dispersal took place by swimming and/or wading from coast to coast, possibly via 488 ephemeral small islands, perpendicular to currents. No migration event would have occurred 489 between Iberia and Morocco during the mid-Upper Pleistocene. According to Straus ( 2001) it is 
490 only in the terminal Paleolithic (10,500-12,000 ya) that, "with clear evidence of marine fishing 491 and probable navigation, a credible case can be made for trans-Gibraltar human contacts". 492 However more recent studies, taking into account the new Aterian chronology, do not support 493 this result (Derricourt 2005; Garcea 2004). During the Mesolithic (9,000 ya), Neolithic and after, 494 numerous contacts between the two shores of the Mediterranean sea occurred, due to the development of navigation (Mulazzani et al. 2010; Souville 1998). Human genetic data also indicates that crossing of the strait of Gibraltar occurred for humans about 9,000 ya (Achilli et al. 2005; Semino et al. 2004). Divergence values between European and Moroccan wood mice are too small to be consistent with dispersal during the Early Pleistocene. The time of divergence obtained between European and North African population (85,000-165,000 ya) is greater than the point estimates obtained for the time of expansion in North Africa according to mismatch mtDNA analyses (between 7,319 and 30,596 ya [CI: 819-45,259]) and MiGRAINE microsatellites analyses (135 ya [CI: 1-344,000])). MigRAINE mtDNA point estimates tended to be higher $(125,000$ ya [CI: $22,000-340,000])$, but with a low precision. It is very difficult to obtain robust age estimates for recent divergent events and for the start of a past expansion for several reasons: 1) the difficulty to robustly estimate mutation rate;2) large confidence intervals are obtained with MigRAINE for the dating of the expansion. Those large confidence intervals are partly due to the lack of information in the data but also to the model of continuous exponential increase. Contrarily to sudden expansions, two exponentially growing populations with an expansion starting at different moments but with a similar change in effective population sizes will lead to very similar patterns of polymorphism because of the shape of the exponential. For example, Leblois et al. (2014) showed that the precision of the inference of the timing of such past progressive expansion is very limited compared to other parameters and to other demographic scenarios. Confidence intervals obtained from mismatch curves are much narrower than for MigRAINE, probably because of both the sudden expansion model and the statistical method used.

516 discrepancy between divergence and expansion time estimates can be explained by two 517 biological hypotheses:

518 1) A recent expansion from a small area of original 'inoculation', in which the inoculation 519 occurred 85,000-165,000 ya. MIGRAINE estimates of ancestral population size (several hundreds 520 or thousands of individuals) before expansion favor this hypothesis. Wood mice arrival in North 
521 Africa may have been progressive, with plenty individuals arriving during a long period of time, 522 and the demographic expansion would have occurred only thousand years later. However this 523 hypothesis is invalidated by : i) fossil data indicating that the wood mouse arrived during the 524 Holocene in Morocco and Algeria (Stoetzel 2013); ii) trans-Gibraltar human movements are 525 attested only after 9,000 ya (see above); iii) owing to the ability of wood mice to live in 526 numerous habitat types (dense and humid forests, dry pine forests, high mountain cedar forests, 527 meadows, sand dunes near the sea, shrubs; to sea level up to 2,000 m) and to its opportunistic 528 feeding habits (Aulagnier et al. 2008; Kowalski and Rzebik-Kowalska 1991), once it have 529 reached North Africa it would have find suitable conditions to undergone a demographic and 530 spatial expansion throughout the Maghreb. Few local competitors probably existed at that time, 531 other rodent species being present avoiding forests (Meriones shawi (Duvernoy 1842), 532 Lemniscomys barbarus (Linnaeus 1766), Mus spretus Lataste 1883, Dipodillus campestris 533 (Loche 1867), Arvicanthis niloticus ( E. Geoffroy 1803), Psammomys obesus Cretzschmar 1828) 534 (Stoetzel 2013). The commensal species Mus musculus domesticus Schwarz and Schwarz 1943 535 and Rattus spp. were present in North Africa more recently (Stoetzel 2013).

536 2) A colonization event later than $85,000-165,000$ ya. The over-estimation of the time of 537 divergence between European and North African wood mice would be explained by the recent 538 invasion of some European haplotypes already divergent from the other haplotypes. Indeed, 539 refuge regions are generally characterized by a high diversity of mitochondrial types (Avise 540 2000) that evolved separately, and high genetic divergence between Spanish haplotypes is 541 observed in the MJ network (with up to 16 mutations). Moreover, as stated above, Gómez and 542 Lunt (2007) showed that Iberia was not a single refuge during the Pleistocene glacial maxima, 543 but that several Iberian refugia existed. Extensive sampling of wood mice in Iberia would be 544 necessary to test if it has an impact on our estimates of divergence time between European and 545 North African wood mice populations. Moreover it would be interesting to sequence longer 546 sequences, since our estimate of the time of divergence between North African and European 547 wood mouse is only based on a short mtDNA sequence length of $701 \mathrm{bp}$.

548 When divergence between lineages is recent, it is difficult to obtain robust age estimates, and 549 therefore to test the alternative hypotheses of anthropogenic translocation and natural 550 colonization, as already stressed by Husemann et al. (2013). However, for A. sylvaticus, we have 551 the chance to have a good fossil record in Maghreb indicating that the wood mouse arrived 
552 during the Holocene in North Africa (Stoetzel 2009, 2013). While it is recorded from 2,500-4,000

553 ya from the Capelleti cave in Algeria, it is recorded since 7,500-6,000 ya in the Tingitana 554 Peninsula (Kahf-That-El-Ghar, Bou Saria). This result fits our time of expansion, with an older 555 expansion near the Tingitana Peninsula than in Algeria. Taken together, genetic and fossil data 556 are consistent (given the difficulty to accurately date recent divergence events) and favor an 557 anthropogenic translocation from the Iberian Peninsula to Morocco. Moreover our genetic data 558 show that the ancestral population size (before expansion) comprised a high number of 559 individuals, reinforcing the idea that wood mice did not colonize Morocco accidentally through 560 rafting of a few individuals, but via recurrent temporal anthropogenic translocations. At first sight 561 it could be surprising that woodmice colonize North Africa via anthropogenic translocation 562 several thousand years ago, and that its dispersal between the two continents did not continues 563 until today since maritime trade has increased. One hypothesis could be that at the beginning of 564 the Holocene A. sylvaticus was more commensal than today. Molecular and zooarcheological 565 data showed that the commensal species Mus musculus only reached Western Europe during the 566 first millennium BC and onwards, related to the generalization of maritime trade (Bonhomme et 567 al. 2010). The arrival of the house mouse in Western Europe at this time could have led to a shift 568 in the degree of commensality of Apodemus.

Geographical structure in the Maghreb: taxonomical implications

571 Three subspecies were described in North Africa: A. s. rufescens inhabits the High Atlas, the arid

572 forest of the Rif and high plateau of Algeria; A. s. ifranensis is present in the medium Atlas and 573 the region of Oulmès, and A. s. hayi inhabits the Mediterranean regions of the Maghreb (Saint 574 Girons 1974; Saint Girons and Van Bree 1962). Our mitochondrial and microsatellite analyses 575 reveal low variability in the North African lineage from Morocco to Tunisia, and nearly no 576 spatial structuring: 1) no significant pattern of isolation by distance was detected with both 577 genetic markers, 2) AMOVA on mtDNA indicates that most of the genetic variation is 578 partitioned within populations, 3) STRUCTURE and GENELAND clustering analyses based on 579 microsatellite data suggest that North African wood mice form a single population, except 580 perhaps for the Merja Zerga population (strong drift as indicated also by low haplotype 581 diversity), and 4 ) estimates of $F_{\mathrm{ST}}$ among populations were not significantly different from 0 for 582 microsatellite data, and were low for mtDNA data. The number of microsatellite loci used in this 
583 analysis is relatively low and may not confer sufficient power to discern fine-scale structure. The

584 use of additional loci could help to elucidate patterns of genetic structure not identified in this 585 study. However, this great similarity throughout North Africa was already highlighted, on a few 586 number of specimens, by the allozymic study of Filippucci (1992) (Nei's distance, $D=0.008$ ), 587 the mtDNA restriction patterns of Libois (2001) and the cytb sequencing of Michaux (2003). Our 588 data confirm a lack of differentiation, even between animals that were caught either at long 589 distances from each other or in the loci typici of the North African subspecies, i.e., where some 590 genetic differences could a priori be expected. Thus, from a taxonomic point of view, our 591 molecular data reinforce the opinion of Kowalski and Rzebik-Kowalska (1991), who, based on 592 morphological characters, invalidated the taxa A. s. ifranensis and A. s. rufescens and considered 593 that the wood mouse is monotypic throughout the region.

594 Most molecular biogeographical studies performed in North Africa yielded high estimates of 595 genetic diversity, and the majority of taxa exhibited multiple endemic lineages dating back to the 596 Plio-Pleistocene or even longer (reviewed by Husemann et al. 2013; Nicolas et al. 2014). Our 597 results on wood mice are strikingly different, but can easily be explained by its recent 598 colonization of the Maghreb.

599 To conclude, wood mice colonized the Maghreb through the Gibraltar strait, probably during the 600 Mesolithic or slightly after, by recurrent/multiple anthropogenic translocations, and then 601 expanded rapidly throughout North Africa without any geographical structuring. Extensive 602 sampling in Iberia and more genetic markers would be necessary to test the 'refugia within 603 refugia' hypothesis and to obtain more accurate dating of the African time of colonization.

\section{Acknowledgments}

606 This study was supported by the ANR call " 6 ème extinction" project "ANR-09-PEXT-004 and the 607 project CMEP TASSILI MDU 09MDU755. RL and CRB have been partially funded by ANR 608 projects EMILE 09-blan-0145-01 and IM-Model@CORAL.FISH 2010-BLAN-1726-01, and by 609 the Project INRA Starting Group "IGGiPop”. Molecular analyses were supported by the ATM 610 “Taxonomie moléculaire, DNA Barcode et Gestion Durable des Collections", the Service de 611 Systématique Moléculaire of the MNHN (UMS 2700, Paris, France) and the network 612 "Bibliothèque du Vivant" funded by CNRS, MNHN, INRA and CEA (Genoscope). Part of this 613 work was carried out by using the resources from the MNHN UMS 2700, INRA GENOTOUL 
614 and MIGALE bioinformatics platforms and the computing grid of the CBGP lab. We are grateful

615 to all collectors, particularly E. Stoetzel, A. Delapre, L. Tifarouine, A. Rihane. The fieldwork was 616 possible through the collaboration of the "Institut Scientifique de Rabat" (Dr A. El Hassani, A.

617 Qninba, M. Fekhaoui, M. Abderhamane, H. El Brini) and of the "Haut Commissariat aux Eaux et 618 forêts et lutte contre la desertification”. Prof. S. Fahd (University of Tetouan), Prof. H. Aouraghe 619 (University of Oujda), Prof. T. Benazzou (University of Rabat), Prof. S. Doumandji (IRA, E1

620 Harrach Alger), Dr Y. Fernandez-Jalvo and Dr C. Sésé (MNCN, Madrid, Spain) must be thanked 621 for all their support and assistance.

\section{References}

Achilli A, Rengo C, Battaglia V, Pala M, Olivieri A, Fornarino S, Magri C, Scozzari R, Babudri N, Santachiara-Benerecetti AS, Bandelt HJ, Semino O, Torroni A (2005) Saami and Berbers--an unexpected mitochondrial DNA link. Am J Hum Genet 76:883-886.

Andersen BG, Borns Jr. HW (1997) The Ice Age world: An Introduction to Quaternary History and Research with Emphasis on North America and Northern Europe During the Last 2.5 Million Years. Scandinavian University Press, Oslo.

Arambourg C (1962) Les faunes mammalogiques du Pléistocène circumméditerranéen. Quaternaria 6:67-109.

Aulagnier S, Haffner P, Mitchell-Jones AJ, Moutou F, Zima J (2008) Guide des mammifères d'Europe, d'Afrique du Nord et du Moyen-Orient. Delachaux et Niestlé, Paris.

Avise JC (2000) Phylogeography: the history and formation of species. Harvard University press, Cambridge.

Bandelt HJ, Forster P, Rohl A (1999) Median-joining networks for inferring intraspecific phylogenies. Mol Biol Evol 16:37-48.

Blondel J, Aronoson J (1999) Biology and Wildlife of the Mediterranean Region. Oxford

640 Bonhomme F, Orth A, Cucchi T, Rajabi-Maham H, Catalan J, Boursot P, Auffray JC, BrittonDavidian J (2010) Genetic differentiation of the house mouse around the Mediterranean basin: matrilineal footprints of early and late colonization. Proc Biol Sci. 
643

Brandt P, Alpers W, Backhaus JO (1996) Study of the generation and propagation of internal waves in the Strait of Gibraltar using a numerical model and synthetic aperture radar images of the European ERS 1 satellite. J Geophys Res 101:14237-14252.

Brito PH, Edwards SV (2009) Multilocus phylogeography and phylogenetics using sequencebased markers. Genetica 135:439-455.

Carranza S, Arnold EN, Pleguezuelos JM (2006) Phylogeny, biogeography, and evolution of two Mediterranean snakes, Malpolon monspessulanus and Hemorrhois hippocrepis (Squamata, Colubridae), using mtDNA sequences. Mol Phylogenet Evol 40:532-546.

Chapuis M-P, Estoup A (2007) Microsatellite null alleles and estimation of population differentiation. Mol Biol Evol 24:621-631.

Cheylan G (1991) Patterns of Pleistocene turnover, current distribution and speciation among Mediterranean mammals. In: Groves RH, Di Castri F eds., Biogeography of Mediterranean Invasions. Cambridge University Press, Cambridge, pp. 227-262.

Cosson JF, Hutterer R, Libois R, Sara M, Taberlet P, Vogel P (2005) Phylogeographical footprints of the Strait of Gibraltar and Quaternary climatic fluctuations in the western Mediterranean: a case study with the greater white-toothed shrew, Crocidura russula (Mammalia: Soricidae). Mol Ecol 14:1151-1162.

Cuenca-Bescós G, Rofes J, López-García JM, Blain H-A, De Marfá RJ, Galindo-Pellicena MA, Bennásar-Serra ML, Melero-Rubio M, Arsuaga JL, de Castro JMB, Carbonell E (2010) Biochronology of Spanish Quaternary small vertebrate faunas. Quatern Int 212:109-119.

Demirel A, Andrews P, Yalçınkaya I, Ersoy A (2011) The taphonomy and the palaeoenvironmental implications of the small mammals from Karain Cave, Turkey. $J$ Archaeol Sci 38:3048-3059.

Dempster AP, Laird NM, Rubin DB (1977) Maximum likelihood from incomplete data via the EM algorithm. J Roy Stat Soc B 39:1-38.

Derricourt R (2005) Getting "Out of Africa": Sea crossings, land crossings and culture in the hominin migrations. $J$ World Prehist 19:119-132.

Dib C, Faure S, Fizames C, Samson D, Drouot N, Vignal A, Millasseau P, Marc S, Hazan J, Seboun E, Lathrop M, Gyapay G, Morissette J, Weissenbach J (1996) A comprehensive genetic map of the human genome based on 5,264 microsatellites. Nature 380:152-154. 
673 Dobson M (1998) Mammal distributions in the western Mediterranean: the role of human intervention. Mammal Rev 28:77-88.

675 Dobson M, Wright A (2000) Faunal relationships and zoogeographical affinities of mammals in north-west Africa. J Biogeogr 27:417-424.

Dubey S, Michaux J, Brunner H, Hutterer R, Vogel P (2009) False phylogenies on wood mice due to cryptic cytochrome-b pseudogene. Mol Phylogenet Evol 50:633-641.

Ducroz JF, Volobouev V, Granjon L (2001) An assessment of the systematics of arvicanthine rodents using mitochondrial DNA sequences: evolutionary and biogeographical implications. J Mammal Evol 8:173-206.

Duggen S, Hoernle K, van den Bogaard P, Rüpke L, Morgan JP (2003) Deep roots of the Messinian salinity crisis. Nature 422:602-606.

Ellegren H (2000) Heterogeneous mutation processes in human microsatellite DNA sequences. Nat Genet 24:400-402.

Evanno G, Regnaut S, Goudet J (2005) Detecting the number of clusters of individuals using the software STRUCTURE: a simulation study. Mol Ecol 14:2611-2620.

Excoffier L, Laval G, Schneider S (2005) Arlequin ver. 3.0: An integrated software package for population genetics data analysis. Evol Bioinform Online 1:47-50.

Felsenstein J (2004) Inferring phylogenies. Sinauer Associates, Inc, Sunderland, Massachusetts.

Filippucci MG (1992) Allozyme variation and divergence among European, Middle Eastern, and North African species of the genus Apodemus (Rodentia, Muridae). Isr J Zool 38:193218.

Filippucci MG, Macholan M, Michaux JR (2002) Genetic variation and evolution in the genus Apodemus (Muridae: Rodentia). Biol J Linn Soc 75:395-419.

Fons R, Saint Girons MC (1993) Le cycle sexuel chez le mulot sylvestre, Apodemus sylvaticus (L., 1758), (Muridae) en région méditerranéenne. Z Säugetierk 58:38-47.

Frezal L, Leblois R (2008) Four years of DNA barcoding: current advances and prospects. Infect Genet Evol 8: 727-736.

$\mathrm{Fu}$ YX (1997) Statistical tests of neutrality of mutations against population growth, hitchhiking and background selection. Genetics 147:915-925.

Garcea E (2004) Crossing deserts and avoiding seas: Aterian North African-European relations. $J$ Anthropol Res 60:27-53. 
704 Gemmeke H, Radtke M, Niethammer J (1987) Zur innerartlichen Proteinvariation bei der 705 Waldmaus (Apodemus sylvaticus). Z Säugetierkunde 52:242-247.

Gómez A, Lunt DH (2007) Refugia within Refugia: patterns of Phylogeographic Concordance in the Iberian Peninsula. In: Weiss N, Ferrand N eds., Phylogeography of Southern European Refugia. Springer, Dordrecht, pp. 155-188.

Goudet J (1995) FSTAT: a computer program to calculate F-statistics. J Hered 86:485-486.

Goudet J, Raymond M, de Meeüs T, Rousset F (1996) Testing differenciation in diploid populations. Genetics 144:1933-1940.

Groves RH, Di Castri F (1991) Biogeography of Mediterranean invasions. Cambridge University Press, Cambridge.

Guillaumet A, Pons JM, Godelle B, Crochet PA (2006) History of the Crested Lark in the Mediterranean region as revealed by mtDNA sequences and morphology. Mol Phylogenet Evol 39:645-656.

Guillot G, Mortier F, Estoup A (2005) GENELAND: a program for landscape genetics. Mol Ecol Notes 5:712-7115.

Habel JC, Dieker P, Schmitt T (2009) Biogeographical connections between the Maghreb and the Mediterranean peninsulas of southern Europe. Biol J Linn Soc 98:693-703.

Harich N, Benazzou T (1990) Contribution à l'étude de la biologie du mulot (Apodemus sylvaticus, Rongeurs, Muridés) de la plaine côtière du Maroc. Mammalia 54: 47-59

Harr B, Musolf K, Gerlach G (2000) Characterization and isolation of DNA microsatellite primers in wood mice (Apodemus sylvaticus, Rodentia). Mol Ecol 9:1664-1665.

Heaney LR (1986) Biogeography of mammals in SE Asia: estimates of rates of colonization, extinction and speciation. Biol J Linn Soc 28:127-165.

Ho SYw, Phillips MJ, Cooper A, Drummond AJ (2005) Time dependency of molecular rate estimates and systematic overestimation of recent divergence times. Mol Biol Evol 22:1561-1568.

Husemann M, Schmitt T, Zachos FE, Ulrich W, Habel JC (2013) Palaearctic biogeography revisited: evidence for the existence of a North African refugium for Western Palaearctic biota. J Biogeogr 41:81-94.

Jaeger JJ (1975) Les Rongeurs, du Miocène à l'actuel, en Afrique nord-occidentale. Université des Sciences et Techniques du Languedoc, Montpellier. 
735 Jojić V., Bugarski-Stanojević V., Blagojević J. Vujošević M. (2014) Discrimination of the sibling species Apodemus flavicollis and A. sylvaticus (Rodentia, Muridae). Zoologischer Anzeiger 253: 261-269.

Jombart T (2008) adegenet: a R package for the multivariate analysis of genetic markers. Bioinformatics 24:1403-1405.

Kimura M (1968) Evolutionary rate at molecular level. Nature 217:624-626.

Kowalski K, Rzebik-Kowalska B (1991) Mammals of Algeria. Polish Academy of Sciences, Institute of Systematics of Evolution of Animals, Wrodow.

Krijgsman W, Hilgen FJ, RaY I, Sierro FJ, Wilson DS (1999) Chronology, causes and progression of the Messinian salinity crisis. Nature 400:652-655.

Lalis A, Leblois R, Lecompte E, Denys C, Ter Meulen J, Wirth T (2012) The impact of human conflict on the genetics of Mastomys natalensis and Lassa virus in West Africa. PLoS ONE 7:e37068.

Langgut D, Almogi-Labin A, Bar-Matthews M, Weinstein-Evron M (2011) Vegetation and climate changes in the South Eastern Mediterranean during the Last Glacial-Interglacial cycle (86 ka): new marine pollen record. Quat Sci Rev 30:3960-3972.

754 Libois RM, Michaux JR, Ramalhinho MG, Maurois C, Sara M (2001) On the origin and systematics of the northern African wood mouse (Apodemus sylvaticus) populations: a comparative study of mtDNA restriction patterns. Can J Zool 79:1503-1511.

Makova KD, Patton JC, Chesser RK, Krysanov EY, Baker RJ (1998) Microsatellite markers in wood mouse and striped field mouse (genus Apodemus). Mol Ecol 7:247-248.

Mantel N (1967) The detection of disease clustering and generalized regression approach. Cancer Res 27:209-220.

Michaux J, Pasquier L (1974) Dynamique des populations de mulots (Rodentia, Apodemus) en Europe durant le Quaternaire. Premières données. Bull Soc Geol France 164:431-439. 
765 Michaux JR, Libois R, Filippucci MG (2005) So close and so different: comparative phylogeography of two small mammal species, the yellow-necked fieldmouse (Apodemus flavicollis) and the woodmouse (Apodemus sylvaticus) in the Western Palearctic region. Heredity 94:52-63.

Michaux JR, Libois R, Paradis E, Filippucci MG (2004) Phylogeographic history of the yellownecked fieldmouse (Apodemus flavicollis) in Europe and in the Near and Middle East. Mol Phylogenet Evol 32:788-798.

Michaux JR, Magnanou E, Paradis E, Nieberding C, Libois R (2003) Mitochondrial phylogeography of the Woodmouse (Apodemus sylvaticus) in the Western Palearctic region. Mol Ecol 12:685-697.

Migowski C, Stein M, Prasad S, Negendank JFW, Agnon A (2006) Holocene climate variability and cultural evolution in the Near East from the Dead Sea sedimentary record. Quaternary Res 66:421-431.

Mulazzani S, Le Bourdonnec F-X, Belhouchet L, Poupeau G, Zoughlami J, Dubernet S, Tufano E, Lefrais Y, Khedhaier R (2010) Obsidian from the Epipalaeolithic and Neolithic eastern Maghreb. A view from the Hergla context (Tunisia). J Archaeol Sc 37:2529-2537.

Myers N, Mittermeier RA, Mittermeier CG, da Fonseca GAB, Kent J (2000) Biodiversity hotspots for conservation priorities. Nature 403:853-858.

Nabholz B, Glemin S, Galtier N (2008) Strong variations of mitochondrial mutation rate across mammals--the longevity hypothesis. Mol Biol Evol 25:120-130.

Nicolas V, Ndiaye A, Benazzou T, Souttou K, Delapre A, Denys C (2014) Phylogeography of the North African dipodil (Rodentia: Muridae) based on cytochrome-b sequences. J Mammal 95:241-253.

Olson DM, Dinerstein E (2002) The global 200: priority ecoregions for global conservation. Ann Missouri Bot Gard 89:199-224.

Posada D, Crandall KA (2001) Intraspecific gene genealogies: trees grafting into networks. Trends Ecol Evol 16:37-45.

Pritchard JK, Stephens M, Donnelly P (2000) Inference of population structure using multilocus genotype data. Genetics 155:945-959. 
794 Recuero E, Iraola A, Rubio X, Machordom A, Garcia-Paris M (2007) Mitochondrial differentiation and biogeography of Hyla meridionalis (Anura : Hylidae): an unusual phylogeographical pattern. J Biogeogr 34:1207-1219.

Rogers AR, Harpending H (1992) Population growth makes waves in the distribution of pairwise genetic differences. Mol Biol Evol 9:552-569.

Rolland N (2013) Europe was peopled independently by converging population movements from both the Western Asian and Ibero-Moroccan staging posts during the Early Pleistocene. Quatern Int 316:59-72.

Rousset F (1997) Genetic differentiation and estimation of gene flow from F-statistics under isolation by distance. Genetics 145:1219-1228.

Saint Girons MC (1974) Rongeurs, lagomorphes et insectivores du Massif du Toubkal (Haut Atlas marocain). Bull Soc Sci Nat Ph Maroc 54:55-59.

Saint Girons MC, Van Bree PJH (1962) Recherches sur la répartition et la systématique de Apodemus sylvaticus (Linnaeus 1758) en Afrique du Nord. Mammalia 26:478-488. C, Shen P, Oefner PJ, Zhivotovsky LA, King R, Torroni A, Cavalli-Sforza LL, Underhill PA, Santachiara-Benerecetti AS (2004) Origin, diffusion, and differentiation of Ychromosome haplogroups $\mathrm{E}$ and $\mathrm{J}$ : inferences on the neolithization of Europe and later migratory events in the Mediterranean area. Am J Hum Genet 74:1023-1034.

Sikes RS, Gannon WL, the Animal Care and Use Committee of the American Society of Mammalogists (2011) Guidelines of the American Society of Mammalogists for the use of wild mammals in research. J Mammal 92:235-253.

Souville G (1998) Contacts et échanges entre la péninsule Ibérique et le Nord-Ouest de l'Afrique durant les temps préhistoriques et protohistoriques. CR Acad Inscr Belle 142:163-177.

Stöck M, Sicilia A, Belfiore NM, Buckley D, Lo Brutto S, Lo Valvo M, Arculeo M (2008) PostMessinian evolutionary relationships across the Sicilian channel: Mitochondrial and nuclear markers link a new green toad from Sicily to African relatives. BMC Evol Biol 8:56-56.

Stoetzel E (2009) Les microvertébrés du site d'occupation humaine d'El Harhoura 2 (Pléistocène supérieur-Holocène, Maroc) : systématique, évolution, taphonomie et paléoécologie. Muséum national d'Histoire naturelle, Paris. PhD Thesis. 
825 Stoetzel E (2013) Late Cenozoic micromammal biochronology of northwestern Africa. $826 \quad$ Palaeogeogr Palaeoclimatol Palaeoecol 392:359-381.

827 Straus LG (2001) Africa and Iberia in the Pleistocene. Quatern Int 75:91-102.

828 Sun JX, Helgason A, Masson G, Ebenesersdottir SS, Li H, Mallick S, Gnerre S, Patterson N, 829 Kong A, Reich D, Stefansson K (2012) A direct characterization of human mutation $830 \quad$ based on microsatellites. Nat Genet 44:1161-1165.

831 Tchernov E (1979) Polymorphism, size trends and Pleistocene paleoclimatic response of the 832 subgenus Sylvaemus (Mammalia: Rodentia) in Israel. Israel J Zool 28:131-159.

833 Trian DA, DeWoody A (2007) The occurrence, detection, and avoidance of mitochondrial DNA 834 translocations in mammalian systematics and phylogeography. J Mammal 88: 908-920

835 Weir BS, Cockerham CC (1984) Estimating F-statistics for the analysis of population structure. $836 \quad$ Evolution 38:1358-1370.

837

838 


\section{Figure legends}

840 Fig. 1: Map showing the actual geographical distribution of the wood mouse (grey shading), the 3 841 potential colonization routes of North Africa discussed in the text and the four main clades 842 recovered in the Median Joining network analysis (A), and the sampling localities in North

843 Africa (B). Localities codes: 1 = BenSlimane, 2 = SidiBoughaba, 3 = MerjaZerga, $4=$ Esperada, 8445 = Tétouan, $6=$ Chrouda, $7=$ BeniHadifa, $8=$ Ketama, $9=$ Parc Talassemtane, $10=$ ElKhizana, $84511=$ Ifrane, $12=$ Moyen Atlas, $13=$ Taza, $14=$ Zeralda, $15=$ Cap Djinet, $16=$ Ain Dram. 846 Localities with only mtDNA data are in black, and localities with both mtDNA and microsatellite 847 data are in grey.

849 Fig. 2: Minimum spanning network of A. sylvaticus cytb haplotypes, with geographic provenance 850 of haplotypes. The area of the circle is proportional to the haplotype frequency, and the length of 851 connecting lines to the distance between haplotypes, defined as the number of substitutions 852 estimated by NETWORK v4.500 (Bandelt et al. 1999). Specimens from Spain are in black.

854 Fig. 3: Apodemus sylvaticus populations clustering based:

855 A. on STRUCTURE Bayesian inference ( $\mathrm{K}=1$ to 6 ); Burn-in period = 150,000; MCMC repeat 856 length $=350,000)$. Graph illustrating the $\log$ posterior probabilities of the microsatellite data (Ln $857 \mathrm{P}(\mathrm{K}))$ for each number of genetic groups $(\mathrm{K})$ tested for 5 runs each. The likelihood $(\mathrm{LnP}(\mathrm{K}))$ and 858 the number of contributing populations was tested using the ad-hoc Evanno statistic (DeltaK) for $859 \mathrm{~K}=1$ to 6 . For $\mathrm{K} 2$ to $\mathrm{K} 5$, each color represents one assumed population cluster K. Multiple 860 colored bars display an individual's estimated membership proportion in more than one 861 population $(\mathrm{q})$, i.e. the admixture level.

862 B. on GENELAND spatial assignments to clusters for $K=2$. The highest membership values are 863 in light yellow and the isolines (grey curves) illustrate the spatial changes in assignment values. 864 The labels correspond to the sampling location indicated in table 7. 


\section{Supporting Information}

867 Figure S1: Minimum spanning network of $A$. sylvaticus Cytb haplotypes.

869 Figure S2 : Observed and expected mismatch distributions under different models (cytb data).

Figure S3: bidimensional plots of likelihood ratio profiles for pairs of parameters inferred by MIGRAINE.

873 Table S1: List of specimens used in this study, with geographical origins, field numbers, voucher 874 numbers of museum collection, haplotype numbers and GenBank accession numbers.

876 Table S2 : Fst values between pairs of populations recorded with the cytb data.

877 Table S3. Estimates of diversity for six nuclear microsatellites per population and per locus.

879 Table S4: FST statistics calculated between each pair of populations for microsatellite data. 880 
881 Table 1: Diversity estimates and demographic history of the wood mouse based on the cytb gene.

882 Estimates for the four main wood mice lineages recovered in our phylogenetic analyses, and for 883 the four populations of the lineage $2 \mathrm{~b}$ with greater sample size were based on $701 \mathrm{bp}$. Estimates 884 for North African populations were based on 864 bp. Number of sequences $(N)$, number of 885 polymorphic sites $(S)$, number of haplotypes $(h)$, haplotype diversity $(H d)$, nucleotide diversity $886(P i)$, average number of nucleotide differences $(k)$. For North Africa, values of $H d, P i, k$ and Fu's

887 Fs are only given for populations with more than 10 individuals sampled.

\begin{tabular}{|c|c|c|c|c|c|c|c|}
\hline & $\mathrm{N}$ & $\mathrm{S}$ & $\mathrm{h}$ & $\mathrm{Hd}$ & $\mathrm{Pi}$ & $\mathrm{k}$ & Fu's Fs \\
\hline \multicolumn{8}{|c|}{ Estimates based on $701 \mathrm{bp}$ (whole geographical range of the species) } \\
\hline Lineage 1a & 44 & 79 & 34 & $0.984 \pm 0.009$ & $0.01067 \pm 0.00178$ & 7.477 & \\
\hline Lineage $1 b$ & 15 & 38 & 14 & $0.990 \pm 0.028$ & $0.01233 \pm 0.00133$ & 8.581 & \\
\hline Lineage $2 a$ & 298 & 125 & 125 & $0.959 \pm 0.007$ & $0.00419 \pm 0.00019$ & 2.938 & \\
\hline Lineage $2 b$ & 188 & 127 & 112 & $0.978 \pm 0.005$ & $0.00887 \pm 0.00047$ & 6.215 & \\
\hline Montseny (Spain) & 16 & 31 & 15 & $0.992 \pm 0.025$ & $0.00907 \pm 0.00102$ & 6.358 & \\
\hline Murcia (Spain) & 18 & 21 & 13 & $0.948 \pm 0.039$ & $0.00524 \pm 0.00090$ & 3.667 & \\
\hline Saint-Benoit (France) & 16 & 5 & 5 & $0.767 \pm 0.080$ & $0.00247 \pm 0.00025$ & 1.733 & \\
\hline South Sweden (Sweden) & 28 & 6 & 3 & $0.667 \pm 0.039$ & $0.00362 \pm 0.00034$ & 2.540 & \\
\hline \multicolumn{8}{|c|}{ Estimates based on 864 bp (North Africa) } \\
\hline & 298 & 136 & 144 & $0.977 \pm 0.005$ & $0.00399 \pm 0.00016$ & 3.449 & $-26.248(P<0.001)$ \\
\hline Cap Djinet & 16 & 21 & 12 & $0.942 \pm 0.048$ & $0.00456 \pm 0.00088$ & 3.942 & $-6.371(P<0.001)$ \\
\hline Zeralda & 3 & 1 & 2 & & & & \\
\hline BeniHadifa & 20 & 14 & 10 & $0.895 \pm 0.043$ & $0.00267 \pm 0.00041$ & 2.305 & $-5.240(P=0.003)$ \\
\hline BenSlimane & 7 & 6 & 4 & & & & \\
\hline Chrouda & 40 & 34 & 23 & $0.962 \pm 0.014$ & $0.00462 \pm 0.00041$ & 3.994 & $-14.922(P<0.001)$ \\
\hline ElKhizana & 16 & 24 & 14 & $0.983 \pm 0.028$ & $0.00422 \pm 0.00074$ & 3.65 & $-10.488(P<0.001)$ \\
\hline Esperada & 8 & 5 & 3 & & & & \\
\hline Ifrane & 51 & 45 & 36 & $0.964 \pm 0.017$ & $0.00327 \pm 0.00029$ & 2.824 & $-26.949(P<0.001)$ \\
\hline Ket ama & 4 & 5 & 4 & & & & \\
\hline MerjaZerga & 28 & 11 & 6 & $0.757 \pm 0.049$ & $0.00353 \pm 0.00035$ & 3.053 & $2.538(\mathrm{P}=0.856)$ \\
\hline Moyen-Atlas ISR & 3 & 4 & 3 & & & & \\
\hline ParcTalassemtane & 25 & 23 & 16 & $0.943 \pm 0.030$ & $0.00319 \pm 0.00040$ & 2.757 & $-12.123(P<0.001)$ \\
\hline SidiBoughaba & 1 & & & & & & \\
\hline Taza & 71 & 54 & 40 & $0.975 \pm 0.007$ & $0.00412 \pm 0.00031$ & 3.557 & $-26.529(P<0.001)$ \\
\hline Tétouan & 1 & & & & & & \\
\hline Ain Dram & 4 & 6 & 4 & & & & \\
\hline
\end{tabular}

888 
890 Table 2: Estimated values of Tau, with confidence interval $(\mathrm{P}=0.05)$, obtained in mismatch

891 analyses using ARLEQUIN, and corresponding expansion time in years for three mutation rates

892 and a generation time of 0.5 year. Calibration 1: mutation rate of $1.210^{-07}$ substitution per site

893 per year for the calibration A. mystacinus and A. flavicollis/A. sylvaticus. Calibration 2: mutation

894 rate of $0.910^{-07}$ substitution per site per year for the calibration A. sylvaticus/A. flavicollis.

895 Calibration 3: mutation rate of $1.7610^{-07}$ substitution per site per year according to Nabholtz et

896 al. (2008). The sequence length was $288 \mathrm{bp}$ (only third codon positions were included).

897

\begin{tabular}{|c|c|c|c|c|c|c|c|c|c|c|c|c|}
\hline & & & & & & & & & & & & \\
\hline & & & & \multicolumn{9}{|c|}{ Expansion time (years) } \\
\hline & \multicolumn{3}{|c|}{ Tau } & \multicolumn{3}{|c|}{ Calibration 1} & \multicolumn{3}{|c|}{ Calibration 2} & \multicolumn{3}{|c|}{ Calibration 3} \\
\hline & $\begin{array}{l}\text { Est } \\
\text { val }\end{array}$ & $\begin{array}{l}\text { Low } \\
\text { bound }\end{array}$ & $\begin{array}{l}\text { Up } \\
\text { bound }\end{array}$ & $\begin{array}{l}\text { Est } \\
\text { val }\end{array}$ & $\begin{array}{l}\text { Low } \\
\text { bound }\end{array}$ & $\begin{array}{l}\text { Up } \\
\text { bound }\end{array}$ & $\begin{array}{l}\text { Est } \\
\text { val }\end{array}$ & $\begin{array}{l}\text { Low } \\
\text { bound }\end{array}$ & $\begin{array}{l}\text { Up } \\
\text { bound }\end{array}$ & $\begin{array}{l}\text { Est } \\
\text { val }\end{array}$ & $\begin{array}{l}\text { Low } \\
\text { bound }\end{array}$ & $\begin{array}{l}\text { Up } \\
\text { bound }\end{array}$ \\
\hline Cap djinet & 1,484 & 0,166 & 2,535 & 11020 & 1233 & 18824 & 14287 & 1598 & 24406 & 7319 & 819 & 12503 \\
\hline Beni Hadifa & 1,863 & 0,355 & 3,248 & 13834 & 2636 & 24118 & 17936 & 3418 & 31270 & 9189 & 1751 & 16020 \\
\hline Chrouda & 2,76 & 1,955 & 3,562 & 20495 & 14517 & 26450 & 26572 & 18822 & 34293 & 13613 & 9642 & 17568 \\
\hline ElKhizana & 3,178 & 1,473 & 4,701 & 23599 & 10938 & 34908 & 30596 & 14181 & 45259 & 15674 & 7265 & 23186 \\
\hline Ifrane & 336 & 1,766 & 3,082 & 17346 & 13114 & 22886 & 22490 & 17002 & 29672 & 11521 & 8710 & 15201 \\
\hline $\begin{array}{l}\text { Parc } \\
\text { Talassemtane }\end{array}$ & 2,584 & 1,686 & 3,637 & 19188 & 12520 & 27007 & 24877 & 16232 & 35015 & 12749 & 8316 & 17938 \\
\hline Taza & 2,99 & 2,172 & 3,791 & 22203 & 16128 & 28151 & 28786 & 20911 & 36498 & 14747 & 10713 & 18698 \\
\hline Maghreb & 2,676 & 2,318 & 2,939 & 19871 & 17213 & 21824 & 25763 & 22316 & 28295 & 13198 & 11433 & 14496 \\
\hline
\end{tabular}

898 
899 Table 3 - Inferences on demographic history by the software MiGRAINE on the pooled Moroccan

900 data set. Point estimates and 95\% Confidence intervals (brackets) are reported. Inferred parameters are

901 (1) pGSM, the parameter of the geometric distribution of the Generalized stepwise mutation model

$902\{$ Pritchard, $1999 \# 4576\}$ (2) $\theta=2 N \mu$ and $\theta_{\text {anc }}=2 N_{\text {anc }} \mu$ the scaled current and ancestral population sizes; (3)

$903 \mathrm{D}=\mathrm{T}_{\text {in generation }} / 2 \mathrm{~N}$ the scaled time of when the past change in population size started. All population sizes

904 are expressed as numbers of genes, i.e. haploïd population sizes. See text and MigRAINE manual for

905 details about the settings of the analyses and the models and method used.

906

\begin{tabular}{|c|c|c|c|c|c|}
\hline $\mathrm{N}$ & pGSM & $\theta$ & $\mathrm{D}$ & $\theta$ Aanc & Pop size eq. $\theta / \theta a n c$ \\
\hline \multicolumn{6}{|c|}{ Microsatellites } \\
\hline \multirow[t]{2}{*}{290} & 0.46 & 160 & 0.00042 & 7.1 & 22.3 \\
\hline & {$[0.53-0.6]$} & {$[12-1400]$} & {$[2.2 \mathrm{E}-5-0.123]$} & {$[2.7-10.2]$} & {$[1.8-212]$} \\
\hline \multicolumn{6}{|c|}{ mtDNA } \\
\hline \multicolumn{6}{|c|}{ Deleted problematic sites (67 haplotypes and 81 segregating sites left) } \\
\hline \multirow[t]{2}{*}{275} & NA & 58 & 0.055 & 0.00040 & 150,000 \\
\hline & NA & [39-95] & {$[0.01-0.15]$} & {$[0-2.1]$} & {$[25-900,000]$} \\
\hline \multicolumn{6}{|c|}{ Deleted problematic individuals (67 haplotypes and 81 segregating sites left) } \\
\hline \multirow[t]{2}{*}{229} & NA & 58 & 0.053 & 0.0023 & 26,000 \\
\hline & NA & {$[37-107]$} & {$[0.01-0.15]$} & {$[0-2.0]$} & {$[27-1,000,000]$} \\
\hline
\end{tabular}

907 
908 Table 4. Population polymorphism at six microsatellite loci over the seven populations sampled:

909 sample size $(\mathrm{N})$, Allele richness $\left(\mathrm{A}_{\mathrm{R}}\right)$, observed $\left(\mathrm{H}_{\mathrm{O}}\right)$ and expected heterozygosity $\left(\mathrm{H}_{\mathrm{E}}\right)$, within 910 population coefficient of inbreeding $\left(\mathrm{F}_{\mathrm{IS}}\right)$, and $H W E$ probability that the genotype population 911 conformed to the Hardy-Weinberg equilibrium.

\begin{tabular}{lllllll}
\hline Population & $\boldsymbol{N}$ & $\boldsymbol{A R}$ & $\boldsymbol{H o}$ & $\boldsymbol{H E}$ & Fis & HWE \\
\hline MerjaZerga & 35 & 8 & 0.749 & 0.746 & 0.063 & 1.000 \\
Chrouda & 25 & 8 & 0.778 & 0.753 & 0.069 & 0.993 \\
BeniHadifa & 27 & 8 & 0.564 & 0.600 & 0.078 & 0.975 \\
ParcTalassemtane & 31 & 8 & 0.666 & 0.745 & 0.129 & 1.000 \\
ElKhizana & 23 & 9 & 0.738 & 0.736 & 0.042 & 0.907 \\
Ifrane & 52 & 10 & 0.708 & 0.766 & 0.099 & 1.000 \\
Taza & 92 & 13 & 0.715 & 0.775 & 0.092 & 1.000 \\
\hline
\end{tabular}



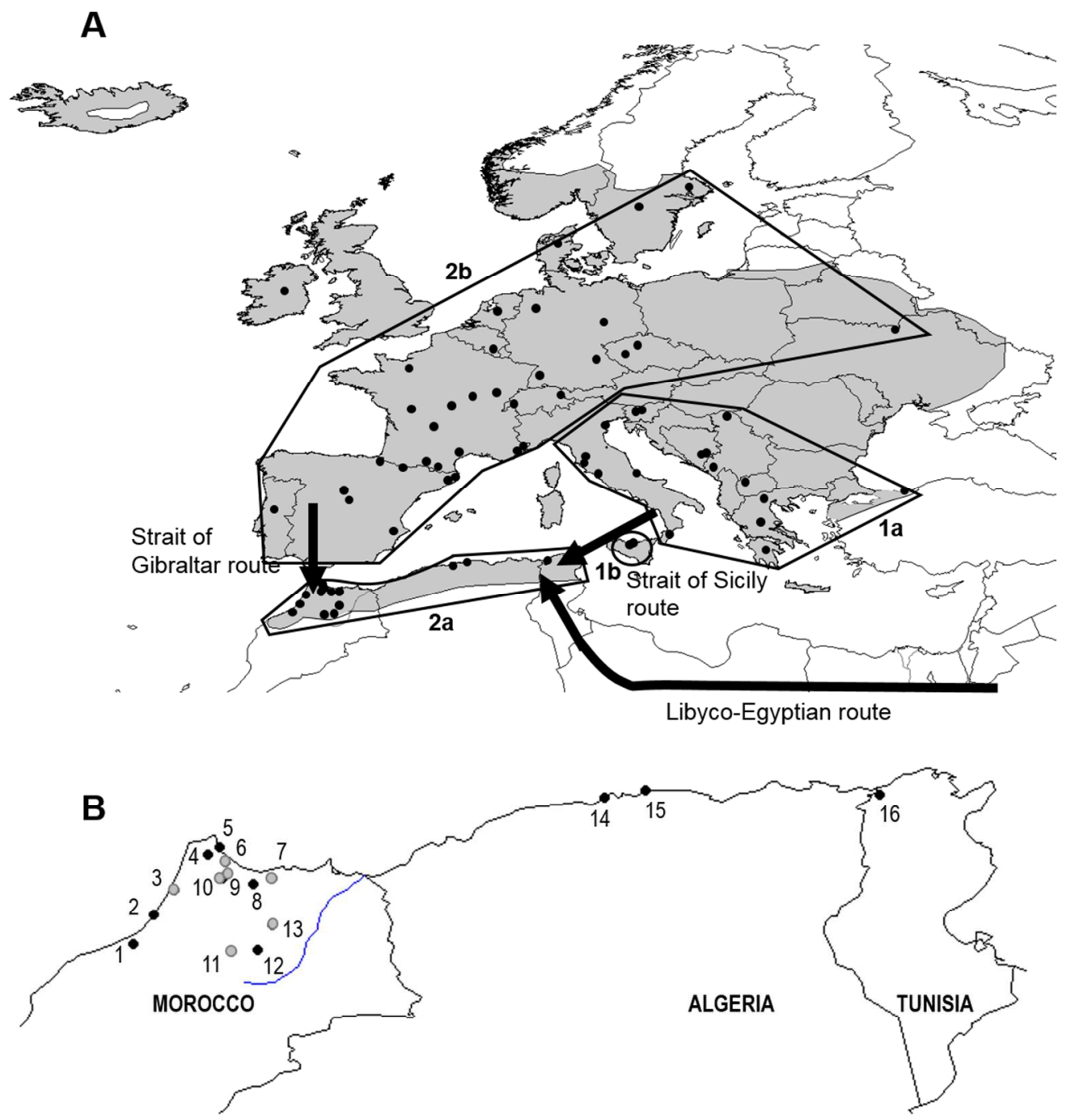

Fig. 1: Map showing the actual geographical distribution of the wood mouse (grey shading), the 3 potential colonization routes of North Africa discussed in the text and the four main clades recovered in the Median Joining network analysis (A), and the localities of collect in North Africa (B). Localities codes: $1=$ BenSlimane, 2 = SidiBoughaba, $3=$ MerjaZerga, $4=$ Esperada, $5=$ Tétouan, $6=$ Chrouda, $7=$ BeniHadifa, $8=$ Ketama, $9=$ Parc Talassemtane, $10=$ ElKhizana, $11=$ Ifrane, $12=$ Moyen Atlas, $13=$ Taza, $14=$ Zeralda, 15 = Cap Djinet, 16 = Ain Dram. Localities with only mtDNA data are in black, and localities with both mtDNA and microsatellite data are in grey. 


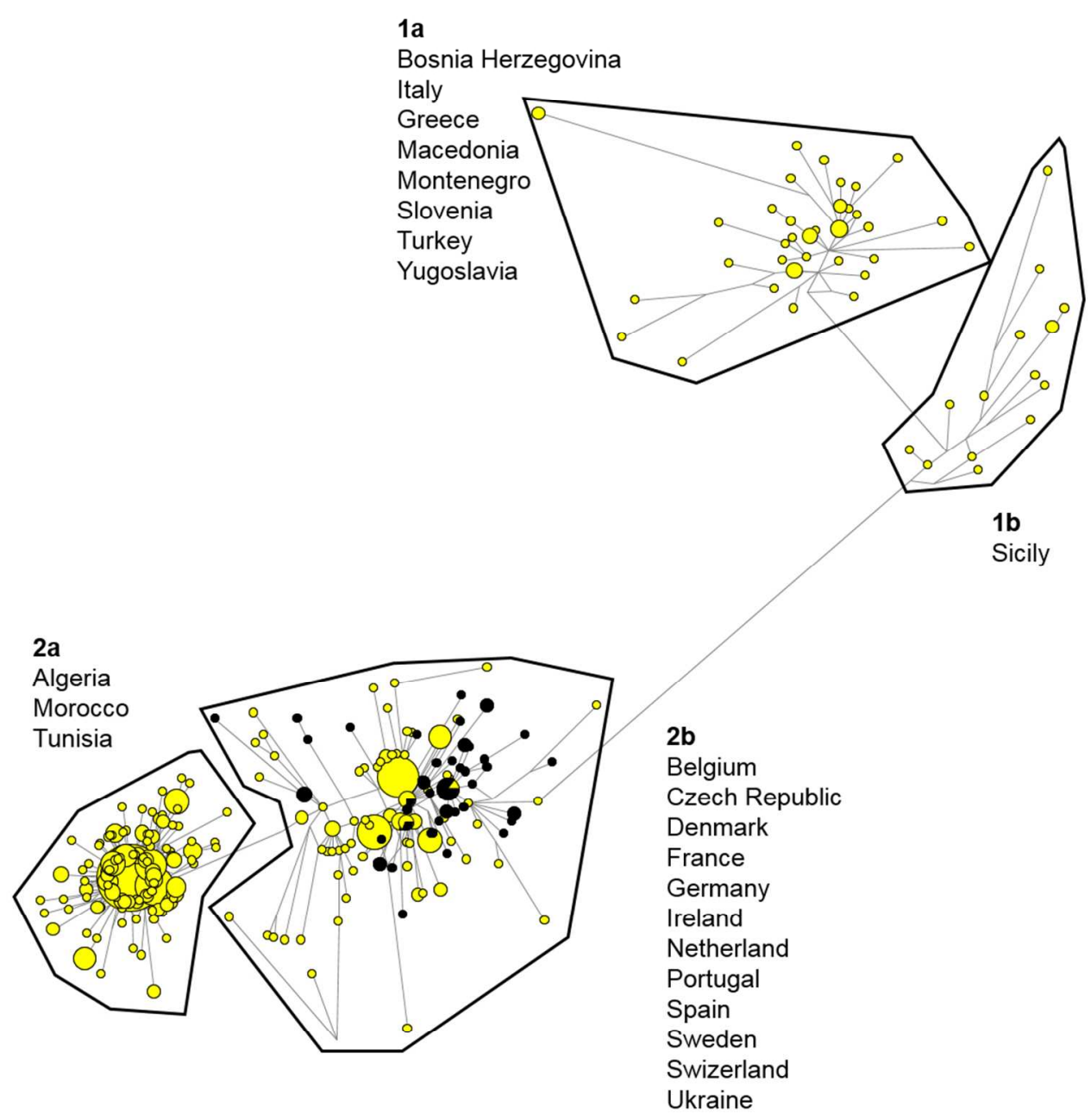

Fig. 2: Minimum spanning network of A. sylvaticus cytb haplotypes, with geographic provenance of haplotypes. The area of the circle is proportional to the haplotype frequency, and the length of connecting lines to the distance between haplotypes, defined as the number of substitutions estimated by NETWORK v4.500 (Bandelt et al. 1999). Specimens from Spain are in black. $188 \times 195 \mathrm{~mm}(150 \times 150 \mathrm{DPI})$ 


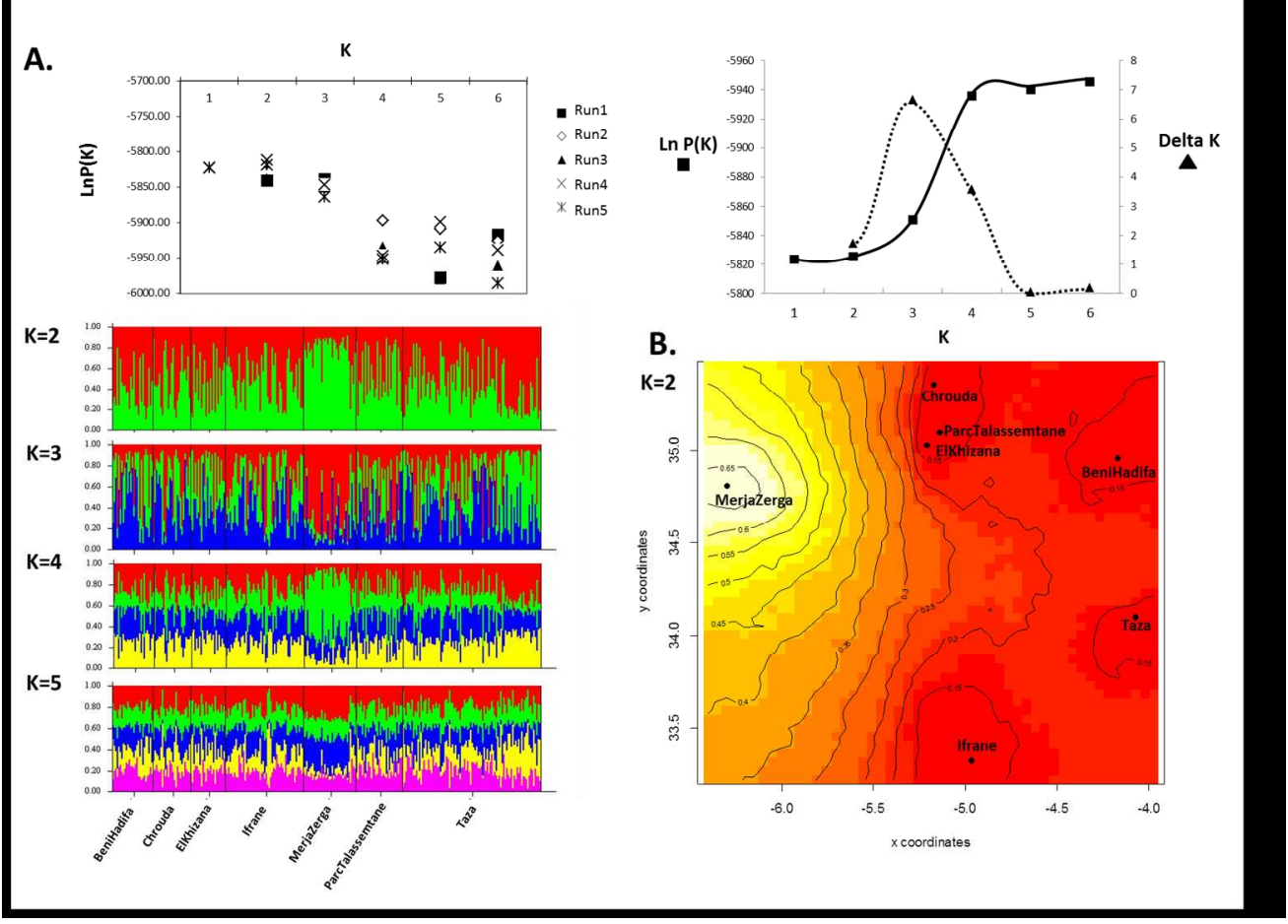

Fig. 3: Apodemus sylvaticus populations clustering based:

A. on STRUCTURE Bayesian inference $(K=1$ to 6$)$; Burn-in period = 150,000; $\mathrm{MCMC}$ repeat length = $350,000)$. Graph illustrating the log posterior probabilities of the microsatellite data ( $L n P(K)$ ) for each number of genetic groups $(K)$ tested for 5 runs each. The likelihood $(\operatorname{LnP}(K))$ and the number of contributing

populations was tested using the ad-hoc Evanno statistic (DeltaK) for $\mathrm{K}=1$ to 6 . For $\mathrm{K} 2$ to $\mathrm{K} 5$, each color represents one assumed population cluster K. Multiple colored bars display an individual's estimated membership proportion in more than one population $(q)$, i.e. the admixture level.

B. on GENELAND spatial assignments to clusters for $\mathrm{K}=2$. The highest membership values are in light yellow and the isolines (grey curves) illustrate the spatial changes in assignment values. The labels correspond to the sampling location indicated in table 7. 